\title{
Qualitative analysis of stroke patients' motivation for rehabilitation
}

\author{
Niall Maclean, Pandora Pound, Charles Wolfe, Anthony Rudd
}

\begin{abstract}
Objective To explore the attitudes and beliefs of stroke patients identified by professionals as having either "high" or "low" motivation for rehabilitation. Design Qualitative study with semistructured interviews.

Setting The stroke unit of an inner city teaching hospital.

Participants 22 patients with stroke who were undergoing rehabilitation; 14 with high motivation for rehabilitation and eight with low motivation.

Results All patients thought rehabilitation was important for recovery. High motivation patients were more likely to view rehabilitation as the most important means of recovery and to accord themselves an active role in rehabilitation. These patients were also more likely to understand rehabilitation and in particular to understand the specialist role of the nursing staff. Many patients reported independence at home as a personal goal, though few low motivation patients related this goal to success in rehabilitation. Information from professionals about rehabilitation, favourable comparisons with other stroke patients, and the desire to leave hospital had a positive effect on motivation. Conversely, overprotection from family members and professionals, lack of information or the receipt of "mixed messages" from professionals, and unfavourable comparisons with other patients had a negative effect.

Conclusions There are some differences in beliefs between stroke patients identified as having low or high motivation for rehabilitation. These beliefs seem to be influenced by the environment in which the patient is rehabilitated. Professionals and carers should be made aware of the ways in which their behaviour can positively and negatively affect motivation.
\end{abstract}

\section{Introduction}

Rehabilitation professionals commonly believe that motivation of patients has an important role in determining outcome, ${ }^{1-3}$ despite the lack of a shared understanding of the term "motivation." ${ }^{4}$ Furthermore, rehabilitation literature shows no consensus on the nature and determinants of motivation. ${ }^{5}$ Most of the clinical literature presents unsupported descriptions of motivation as an individual personality trait, ${ }^{67}$ without any empirical analysis of motivation.

Few studies have attempted such analysis. Kaufman suggested that stroke patients' motivation was increased by their sharing the "ideology" of rehabilitation. ${ }^{89}$ Other studies found that patients sharing this ideology received more attention from rehabilitation professionals. ${ }^{210}$ These studies, however, did not focus on the analysis of motivation and did not explore the attitudes and beliefs associated with motivation. If
General topics covered in interviews with stroke patients

- Confidence about making a good recovery

- Views about relationship with professionals

- Ideas about important factors in recovery

- Ideas about the patient's role in rehabilitation

- Ideas about the nature and purpose of rehabilitation

- Feelings about what sort of life is desired after the stroke

motivation for rehabilitation affects outcome, its nature and aetiology should be better understood.

We explored the beliefs of stroke patients who were identified as having "high" or "low" motivation for rehabilitation and investigated the determinants of their motivation.

\section{Methods}

Design of study-Semistructured interviews ${ }^{11}$ were conducted with stroke patients who were undertaking rehabilitation in the stroke unit of an inner city teaching hospital.

Sample-Patients were selected by using "extreme case sampling," whereby participants considered to be clear examples of the phenomenon under investigation are recruited. ${ }^{12}$ Professionals on the stroke unit identified patients considered to have high or low motivation for rehabilitation. If there was consensus regarding a patient's motivational status (no more than one professional dissenting) the patient was recruited. Patients with severe cognitive or language difficulties or medical conditions held to affect engagement with rehabilitation (for example, depression) were excluded. After nine months of sampling, categories emerging from the analysis of the interviews began to repeat and no new categories were emerging. This was taken to indicate that the most salient issues had been identified, and sampling was discontinued. ${ }^{13}$

Interviews-Interviews were conducted by the patient's bedside at an average of six weeks after the stroke and were tape recorded and transcribed. Each interview covered the same general topics, although the patient was free to structure the conversation within each topic. New topics brought up by the patients were discussed as and when they arose. All interviews were conducted and analysed by the same researcher (NM), who knew whether patients were described as having high or low motivation. A random sample of interviews was analysed by a second member of the study team (PP) to check that there were no differences in the ways in which high and low motivation patients were interviewed.

Analysis-The interviews were analysed by content. ${ }^{14}$ Initially, interview transcripts were read for
Department of Public Health Sciences, Guy's, King's College, and St Thomas's Hospitals Schools of Medicine and Dentistry, King's College, University of London, London SE1 3QD

Niall Maclean research associate Pandora Pound research fellow Charles Wolfe reader

Elderly Care Unit, St Thomas's

Hospital, London

SE1 7EH

Anthony Rudd

consultant in elderly care/stroke

Correspondence to:

N Maclean

macleanniall@

hotmail.com

BMJ 2000;321:1051-4 
emergent themes, which were then coded. Care was taken to ensure the codes accurately captured the respondent's meaning. The codes in each interview were then compared with those in each other interview to create broader categories that linked codes across interviews (constant comparison ${ }^{13}$ ). Again, care was taken to ensure that these broader categories did not distort the respondent's meanings. For example, "it is important to work in rehabilitation"; "my own effort will bring rehabilitation gains"; and "I work with the therapists" are examples of codes of emergent themes, and "I have an active role in rehabilitation" would be the category serving to link these themes.

\section{Results}

\section{Sample}

Fourteen patients were identified as having high motivation and eight as having low motivation. The table gives details of the participants.

\section{Patients' views and beliefs}

The role of rehabilitation and the patients' role in rehabilitation-While all the patients thought that rehabilitation had a role in their recovery, many high motivation patients (and only a few low motivation patients) believed that rehabilitation had the most important role. Many patients thought they had an active role in rehabilitation and thought they had to apply effort to make gains. Only low motivation patients thought they ought simply to wait for recovery.

Understanding rehabilitation - A few high motivation patients emphasised the importance of learning to perform rehabilitation exercises in the manner specified by therapists. Only low motivation patients, however, spontaneously reported not understanding the nature of rehabilitation exercises. Though walking was the most commonly reported goal of rehabilitation, some patients reported not understanding the therapeutic process leading towards that goal: "The ultimate aim is to get me walking... I don't understand the steps. How they [the physiotherapists] plan it" (patient 14, low motivation).

The role of nurses in rehabilitation -Many high motivation patients (but no low motivation patients) spontaneously claimed that they understood the specialist role of the stroke unit nurses in rehabilitation: "A lot of the nurses are cruel to be kind. 'There's the bowl, there are your washing things, get on with it' ... I think that's essential" (patient 20, high motivation). Some of these patients criticised nurses for not being more involved in rehabilitation or for overprotecting the patient. In comparison, some low motivation patients spontaneously claimed not to understand the

\section{Characteristics of sample of stroke patients}

\begin{tabular}{lcc} 
Characteristic & High motivation $(\mathbf{n}=\mathbf{1 4})$ & Low motivation $(\mathbf{n}=\mathbf{8})$ \\
\hline Male & 10 & 3 \\
\hline Median (range) age (years) & $72(38-86)$ & $78(54-85)$ \\
\hline White & 10 & 5 \\
\hline Black Caribbean & 2 & 2 \\
\hline Black African & 0 & 1 \\
\hline Asian & 2 & 0 \\
\hline Median (range) Barthel score ${ }^{*}$ at interview & $14 / 20(4-19)$ & $7 / 20(3-10)$
\end{tabular}

*Barthel score: 0-14=moderate/severe disability; 15-19=mild disability; $20=$ independent. nurses' role in rehabilitation and expressed frustration that the nurses didn't do things for them.

Independence as a rehabilitation goal-Many high motivation patients were worried about depending on others after they left hospital. Most of these patients thought that progress in rehabilitation meant developing independence in activities of daily living. Some low motivation patients also expressed independence as a goal, although few linked this goal to progress in rehabilitation.

\section{Influences on patients' beliefs}

Some patients spontaneously reported that a range of factors affected their beliefs about rehabilitation.

Overprotection - A few patients reported overprotection from family members or stroke unit nurses, or both, which made them feel "stupid" and incapable. One low motivation patient, who expressed independence as a goal, described how her daughter convinced her that rest (not rehabilitation) was the most appropriate treatment.

Comparisons with other patients-One patient took the example of a stroke patient who recovered well as a source of confidence in her own recovery. Other patients, however, reported feeling depressed at the fact they were not rehabilitating as well as other patients.

Information from professionals-The informationgiving role of the professionals on the stroke unit was emphasised by many high motivation patients and comparatively few low motivation patients. Some high motivation patients described how information from staff led their thinking away from any "magic" solution to their problems (for example, "miracle drugs"), to focus instead on taking an active role in rehabilitation. One such patient reported how information about the rehabilitation plan helped to keep him determined: "I'm determined, yes. The physios are very good here, they're very encouraging and they explain things to you. Cos you don't know what the plan is, do you, unless they tell you. So then you know all the pain and everything is worth it" (patient 17, high motivation). Other high motivation patients explained how information helped them to understand rehabilitation goals and to recognise when they were making progress. This provided reassurance that rehabilitation was working.

The need for information and support-Many low motivation patients reported anxieties that they thought stemmed from a lack of information and support from professionals on the stroke unit. One patient described how she felt less personally involved because she did not understand her rehabilitation exercises, and another described being too afraid to participate in rehabilitation because of her lack of understanding. She thought information and encouragement from therapists would help. Some patients who wanted to leave hospital also reported uncertainties over how they would cope at home. One related this anxiety to what he perceived as a lack of information from staff and described how this compromised his desire to participate in rehabilitation: "These doctors don't give you too much information ... only say 'Oh you're going home' and that's it ... And when it happens again, that's it, back to square one, which would be a waste of time going to a gym ... it's a strain on your mind all the time, 
we're doing this for nothing" (patient 9, low motivation). In addition, a few low motivation patients felt unable to speak out against what they saw as the stroke professionals' decisions, for fear of being rejected by staff.

Mixed messages - A few low motivation patients described some of the stroke unit professionals as giving out unhelpful "mixed messages." One patient reported that physiotherapists encouraged her to work at rehabilitation. On returning to the ward, however, she thought the nurses discouraged such effort by putting her to bed. This resulted in confusion regarding the correct way to behave. "The help was good downstairs [in the physiotherapy gym] but when I come up here, I go to bed again so what can I do? ... So I don't know what is good or bad ... I just don't know ... you can't bother people just because you want to learn how to walk" (patient 5, low motivation). Another low motivation patient doubted the point of physiotherapy as her leg had been injured when nurses were putting her in a wheelchair. This patient also reported feeling less inclined to attend rehabilitation when she discovered that her goal of returning home was deemed unrealistically high. Another low motivation patient described feeling obliged to let the nurses wash him as this was the "law" in the hospital.

Desire to leave hospital-Almost all the patients wanted to leave hospital as quickly as possible. In addition, some cited this desire as a main motivating factor for doing rehabilitation exercises. Most of these patients resented the institutional feel of the hospital. Some complained that the ward environment was depressingly unstimulating.

\section{Discussion}

\section{Advantages of study}

The value of qualitative methods in researching patient attitudes is well recognised. ${ }^{15}$ Semistructured interviews that allow patients considerable control over the conversation are an efficient way to investigate an underresearched topic and to allow patients to explain their beliefs accurately in their own terms.

The age, sex, and ethnic mix in our sample suggest that a broad range of viewpoints has been covered. While generalisability is not a central aim of qualitative research, attaining this sort of diversity of opinion is. ${ }^{15}$

\section{Limitations of study}

Our sample excluded patients with severe linguistic or cognitive impairments and patients diagnosed with disorders that we considered would affect motivation (for example, depression) - a sizeable proportion of stroke patients. ${ }^{16}$

As we interviewed patients who had been identified as having high or low motivation, it might seem that we have sampled patients who happen to fall under professional labels rather than those who actually are motivated or unmotivated. There is no consensus, however, regarding what motivation actually is. ${ }^{5}$ Use of clinical judgment about which patients are motivated or unmotivated is a reasonable way to begin to investigate motivation empirically.

\section{What is already known on this topic}

Rehabilitation professionals have long held that patient motivation affects outcome, but little research has been conducted into the nature of motivation

Clinical rehabilitation literature has relied on unsupported models of motivation as a character trait of the individual patient

If motivation affects outcome, its nature and determinants ought to be better understood

\section{What this study adds}

Patients with stroke identified as having high motivation for rehabilitation were found to align themselves more closely to the aims and methods of rehabilitation professionals, and were more likely to understand the nature and purpose of their rehabilitation, than those identified as having low motivation

Information about rehabilitation, favourable comparisons with other stroke patients, and the desire to leave hospital were positive determinants of motivation; overprotection from family members and professionals, lack of information and the provision of mixed messages about rehabilitation to patients, and unfavourable comparisons with other patients were negative determinants of motivation

Rehabilitation professionals and carers ought to be aware of the ways in which their behaviour affects motivation

\section{Clinical implications}

If motivation is linked to understanding rehabilitation (especially understanding the role expected of the patient by rehabilitation professionals), and if this understanding is related to the possession of information about rehabilitation, then motivation might be increased through the provision of more extensive and more efficiently communicated information. When we carried out this study there was no formal provision of information about rehabilitation to patients on the stroke unit. Provision of information to patients could conceivably diminish the negative effects of overprotection, unfavourable comparisons with other patients, and the encouragement of a role at odds with the one prescribed by rehabilitation. In addition, information about setting goals and involving the patient in the process of setting these goals have previously been proposed as positive determinants of motivation. ${ }^{17}{ }^{18}$ It might be especially important for nursing staff to avoid giving out "mixed messages" about what is expected of rehabilitation patients. The constant contact nurses have with patients gives them an important input in rehabilitation. ${ }^{16} 19$

In general, clinical awareness of the ways in which factors beyond the patient's control can affect motivation might reduce the temptation to place sole responsibility for being motivated on to the individual patient. Several studies have suggested that the person- 
ality trait model of motivation prevalent in much of clinical literature, which does place this sort of responsibility on patients, can negatively affect engagement with rehabilitation..$^{20}$

\section{Implications for further research}

Further research into the determinants of motivation is required. Ethnographic research into how patients are treated by rehabilitation professionals on the basis of labels such as "motivated" and "unmotivated," and the effects this might have on motivation, seems warranted. Research into how patients themselves categorise motivation might also be useful. All such research might help in maintaining motivation among rehabilitation patients, a task often taken to be "the most important, yet the most difficult part of the work of the therapeutic professions." ${ }^{22}$

We thank the professionals on the stroke unit, the family members, and most of all the patients who agreed to be interviewed. We also thank Dr Ajay Bhalla.

Contributors: NM refined the study design, performed a literature search, conducted and analysed the interviews, wrote the paper, and is guarantor. $\mathrm{PP}, \mathrm{CW}$, and $\mathrm{AR}$ were involved in the original study design, refining the study design, and drafting the paper.

Conflict of interest: None declared.

Funding: The Stroke Association.

1 Gubrium JF, Buckholdt DR. Describing care: images and practice in rehabilitation. Cambridge, MA: Oelgeschlager, Gunn and Hain, 1982

tation. Cambridge, MA: Oelgeschlager, Gunn and Hain, 1982. 1986;22:983-9.

\section{A valuable lesson}

\section{The doctor is on your side}

It had been quite an ordeal already. A winter sports' accident had left me paralysed from the chest down, with numerous other injuries. I had been at a spinal injuries unit for rehabilitation for almost a year, and was being allowed home for weekend leave. A big concern had been a tight tracheal stricture, which had occurred as the result of the insertion of a tracheostomy tube a few days after the accident.

Fortunately, medical friends had found a surgeon who had been able to perform a corrective procedure, which was complex and specialised. This was done about nine months after the accident. The original tracheal reconstructive procedure had been a success, in that the narrowing had been improved, but a tracheostomy remained. I was relieved to have my speech again after so much frustrating silence.

The plan was to keep a tracheostomy in place below the surgical site until the scarring looked mature and the tracheal aperture was acceptable. This involved endoscopic evaluation under general anaesthetic and lasering to areas that looked suspect. Three months was the routine interval between procedures. Having a tracheostomy in itself was a trying experience. Secretions have to be suctioned frequently from the tube. Even though I could now do the suctioning myself, it was still quite burdensome.

The time had come for the first assessment since the major operation. Having recovered from the anaesthetic, the surgeon told me that the scar looked much improved. Lasering had been performed, but the tracheostomy tube needed to stay in until at least the next assessment. I was ambivalent. The outcome of surgery was heading in the right direction. On the other hand, I had a few more months in which to
3 Griffiths L, Hughes D. Typification in a neuro-rehabilitation centre: Scheff revisited? Soc Rev 1993;41:415-45.

4 King P, Barrowclough C. Rating the motivation of elderly patients on a rehabilitation ward. Clin Rehabil 1989;3:289-91.

5 Maclean N, Pound P. A critical review of the concept of patient motivation in the literature on physical rehabilitation. Soc Sci Med 2000;50:495-506.

6 Wolff BB. How do rheumatic diseases relate to economic potential as influenced by: personal attitudes and motivation. Pa Med 1969;72:68-70.

7 Clark MS, Smith DS. Abnormal illness behaviour in rehabilitation from stroke. Clin Rehabil 1997;11:162-70.

8 Kaufman S. Illness, biography, and the interpretation of self following a stroke.J Ageing Stud 1988;3:221-7.

9 Kaufman SR. Towards a phenomenology of boundaries in medicine: chronic illness experience in the case of stroke. Med Anthropol $Q$ 1988;2:338-54.

10 Gold SJ. Getting well: impression management as stroke rehabilitation. Qual Sociol 1983;6:238-54.

11 Gilbert Nigel. Researching social life. London: Sage, 1993.

12 Patton M. How to use qualitative methods in evaluation. Newbury Park: Sage, 1987

13 Strauss A, Corbin J. Basics of qualitative research. Newbury Park: Sage, 1990.

14 Weber R. Basic content analysis. London: Sage, 1990.

15 Fitzpatrick R, Boulton M. Qualitative methods for assessing health care. Qual Health Care 1994;3:107-13.

16 Anderson R. The aftermath of stroke. Cambridge: Cambridge University Press, 1992.

17 Tupper A, Henley S. Predictive factors in stroke outcome and implications for intervention. Int J Rehabil Res 1987;10:119-22.

18 Ibbotson J. Motivation-the occupational therapist's view. Physiotherapy 1978;61:189-91

19 Wade DT. Who looks after stroke patients? Br J Hosp Med 1987;37:200-4.

20 Hoffman JE. Care of the unwanted: stroke patients in a Canadian hospital. In: Coburn D, D'Arcy C, New P, Torrance G, eds. Health and Canadian Society. Markham, ON: Fitzhenry and Whiteside, 1981.

21 Becker G, Kaufman SR. Managing an uncertain illness trajectory in old age: patient's and physician's views of stroke. Med Anthropol $Q$ 1995:9:165-87.

22 O'Gorman G. Anti-motivation. Physiotherapy 1975;61:176-9

(Accepted 3 August 2000) endure a tracheostomy. I was hungry and probably greedy for progress. The surgeon must have sensed this, but it was difficult to discuss this so soon after the operation.

I was at home for the weekend feeling a little downhearted when the telephone rang. It was the surgeon. He explained again why the tracheostomy needed to remain. He empathised with me and said that he disliked tracheostomies and wanted to remove them whenever possible. This reminded me that he was on my side, not that I ever really questioned this. He had made it possible for me to regain my speech. But when you are grasping for every glimmer of progress, especially if not immediately deliverable, it is easy to lose sight of the fact that the doctor is working with you. Empathy and showing a motivation to help as a doctor is vital and may be strengthening for the patient, especially in difficult circumstances. This episode has reminded me of that now that my role is reversed.

Tom Wells senior SHO in oncology, Bristol

We welcome articles of up to 600 words on topics such as A memorable patient, A paper that changed my practice, My most unfortunate mistake, or any other piece conveying instruction, pathos, or humour. If possible the article should be supplied on a disk. Permission is needed from the patient or a relative if an identifiable patient is referred to. We also welcome contributions for "Endpieces," consisting of quotations of up to 80 words (but most are considerably shorter) from any source, ancient or modern, which have appealed to the reader. 